\title{
AN EVALUATION OF ELECTROMAGNETIC METHODS FOR WASTE SITE ASSESSMENT
}

\author{
Louise Pellerin \\ Lawrence Berkeley National Laboratory, \\ 1 Cyclotron Road, MS 90-1116, Berkeley, CA USA 94720 \\ David L. Alumbaugh \\ Sandia National Laboratories, Albuquerque, NM USA \\ M. Cathy Pfeifer \\ Idaho National Engineering Laboratory, Idaho Falls, ID USA
}

\begin{abstract}
SUMMARY
A baseline study in electromagnetic (EM) exploration of the shallow subsurface $(<10 \mathrm{~m})$ was performed at the Idaho National Engineering Laboratory (INEL) Cold Test Pit (CTP) for the purpose of identifying and evaluating existing commercial and experimental instrumentation, integrating those technologies with multidimensional interpretational algorithms, and identifying gaps in shallow subsurface EM imaging technology. Rapid magnetic field systems are excellent anomaly detectors. Electric field measurements are necessary to support currently available multidimensional inversion. A three-component time-domain dataset appears to have a significant amount of information for three dimensional inversion, but no such algorithms have been identified. The eleven systems, filling the geophysical sounding range from ground penetrating radar (GPR) to lowfrequency electrical geometrical techniques are represented in this study as shown below. All data and survey descriptions are available on the world wide web at http://vetem.lbl.gov. Educators and students are encouraged to use the data.
\end{abstract}

\section{THE GEOPHYSICAL ELECTROMAGNETIC SPECTRUM}

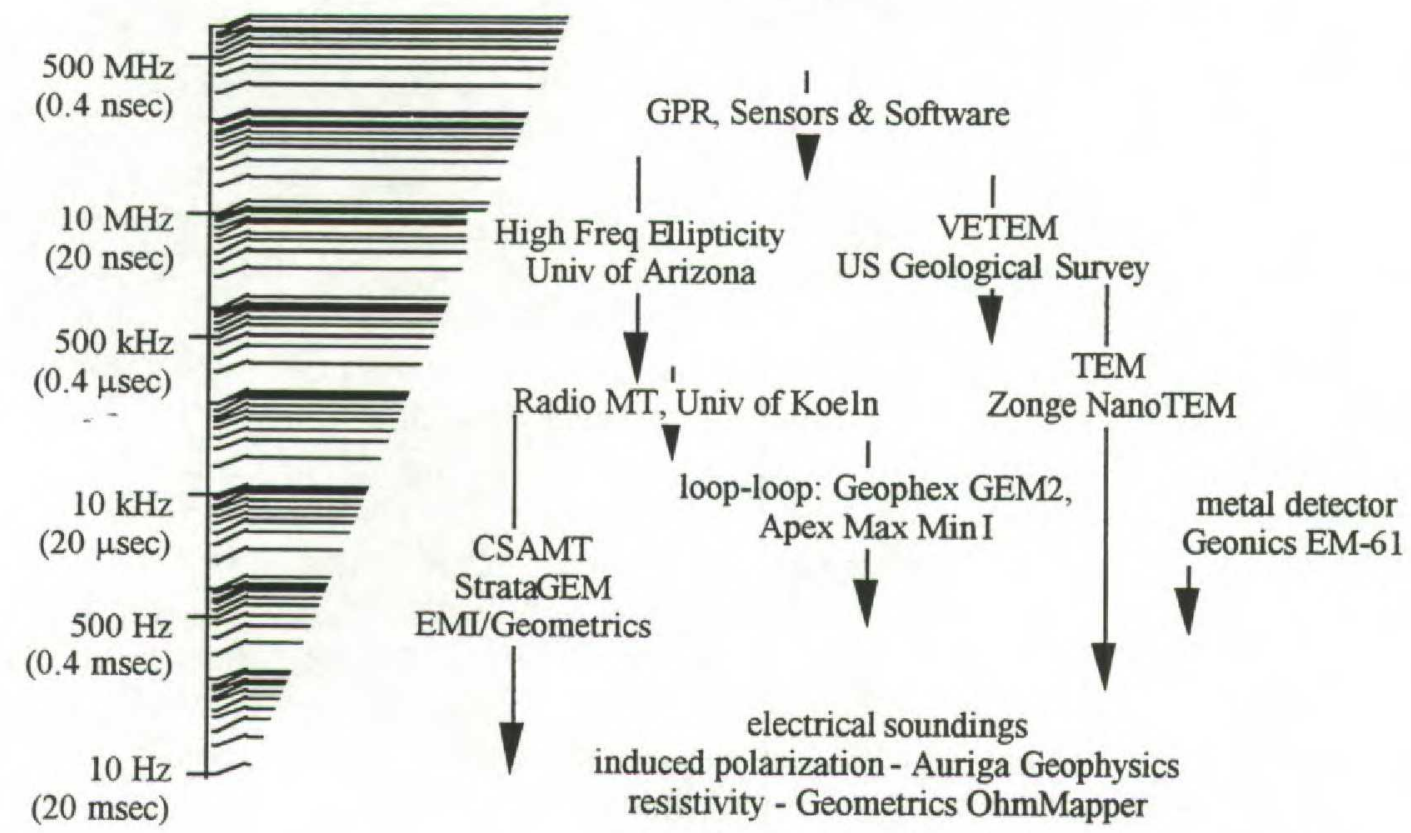




\section{THE INEL COLD TEST PIT}

The INEL CTP was built to demonstrate characterization, stabilization and retrieval technologies for the remediation of buried waste sites. The CTP is located just outside the Radioactive Waste Management Complex on the Snake River plain in south central Idaho, which is in the northwestern USA. Flood basalts compose bedrock at a depth of 20-30 feet from the surface; depth to groundwater is in excess of 500 feet. Variable cap material is 1-2 meters thick. The site has been graded relatively flat, but topography across the survey area on the order of 0.5 meters does exists. The site was chosen by the Department of Energy office responsible for the funding of this project. Full, detailed excavation of the site is planned for ground truth and closure of the project.

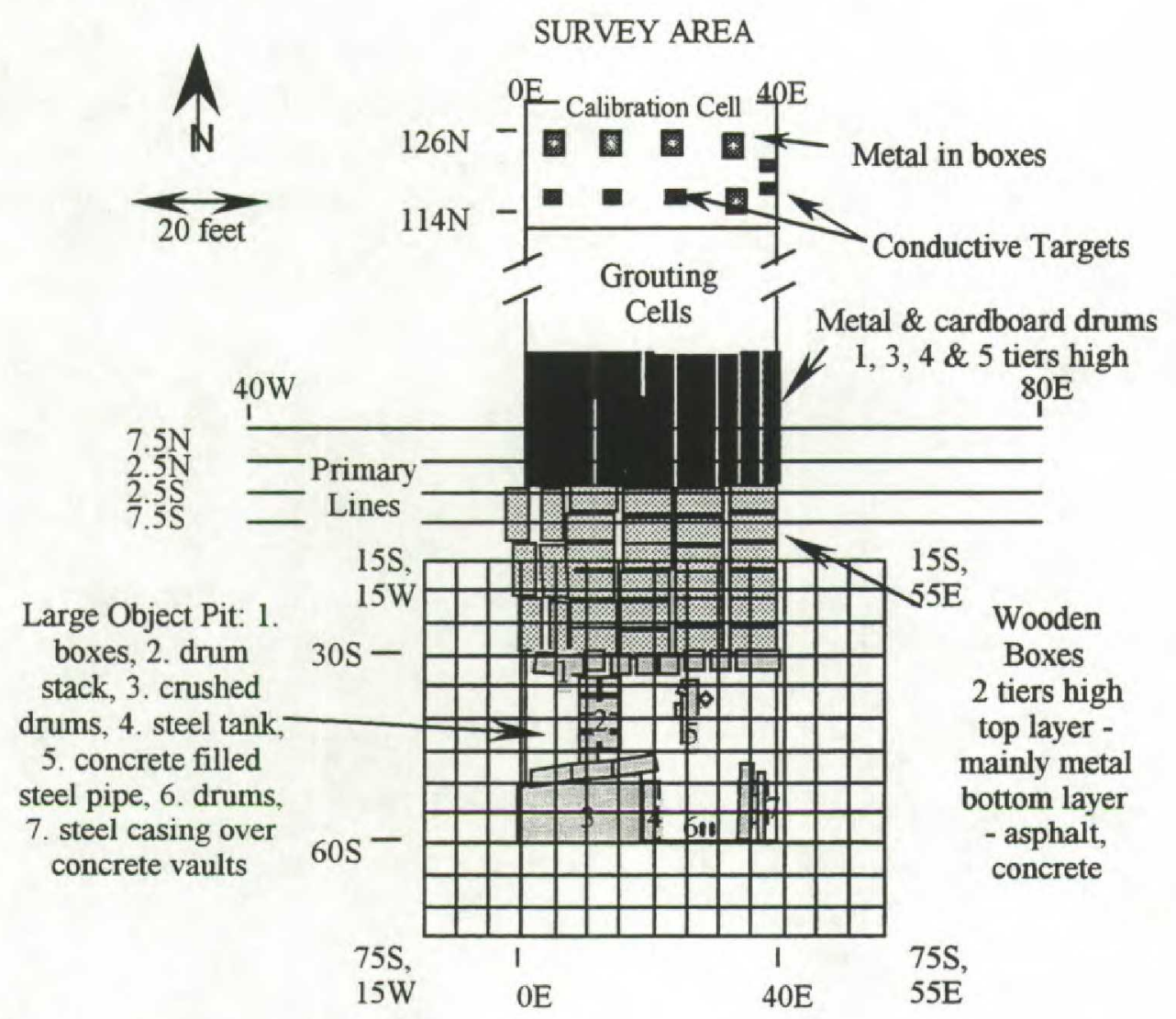

The survey area is shown above. The grid covers the calibration cell to the north and the three southern cells containing: stacked cardboard and metal drums, boxes full of metal and asphalt, and the large object pit with a variety of objects. The mix of cardboard and metal drum was used to simulate a 30 to 40 year old waste pit. The stack of drums varies from 1 to 5 drums deep from west to east respectively. Four profile lines over the box and drum cells, called the primary lines, were used by all participants. A 2-D grid over the large object pit and the calibration cell were used when appropriate. Line spacing is five feet and station spacing along the lines varies with each system, but is staked every 5 feet. Much of the data over the large object pit and calibration cell were acquired with north-south and east-west lines to include both polarization modes of excitation. 


\section{SURVEY DESCRIPTION AND EVALUATION}

Due to unfavorable surface conductivities and high magnetic losses of the soils, the GPR method is ineffective at the INEL. A variety of antennas and array configurations were used with little success. The method was well represented by Sensors and Software, and the results do not reflect the method or the system, as GPR is often problematic where conductive soils are present, such as clay caps over waste pits.

Two systems should enjoy special attention for attempting to fill the critical gap between GPR and traditional diffusive EM: the high frequency ellipticity (HFE) system (Sternberg and Poulton, 1994) and the very early time EM (VETEM) system (Wright et al., 1996). A fundamental problem in working in this range is the earth loads the transmitter changing the calibration of the system and hence the ability of quantified interpretation of the data. The HFE group took an empirical approach by training neural networks with data acquired at a test field facility for data interpretation. The ellipticity parameterization reduces calibration problems and the neural network incorporates the system response into the solution, but problems can occur when the network encounters a dataset for which it is not trained. The VETEM team took a theoretical approach to interpreting data, but the system is still under development and the outcome of this approach is not yet known.

Time domain methods are represented by a metal detector (Geonics EM-61), one of the most popular and widely-used geophysical tools, and a broad-band, three-component (3C) receiver system (Zonge NanoTEM). The EM-61 worked quite well for locating metallic objects, as designed, and contouring of the data is a rapid and appropriate approach. The 3C data were collected with $10 \mathrm{~m} /$ side transmitter and $361 \mathrm{~m}$ receivers/transmitter. Such dense data are not routinely collected, but there is much information is in the horizontal components and interpretation of the broad-band $3 \mathrm{C}$ data is a goal of future work. Inspection of the raw data show that outside of the waste there is about a decade and a half of signal before the transient decays to noise, whereas there is over four decades of signal over the waste areas, indicating that the majority of the signal is coming from currents confined to the conductive waste.

Slingram techniques encompassed systems with both fixed and variable coil separation as with the Geophex GEM2 and Apex Parametrics MaxMin I systems, respectively. A constant separation between the transmitting and receiving loops is critical for accurate measurement of the in-phase component, because of the large contribution of the free-space component. The use of a rigid, fixed-separation system alleviates the problem of exactly locating the coils, but it also eliminates the powerful geometric sounding parameter. We found we could not locate the coils with a variable separation accurately enough for in-phase measurement with separations of 30 feet.

The radio magnetotellurics (RMT) from the University of Koln and controlled source audio magnetotellurics (CSAMT) system from EMI/Geometrics represent plane wave techniques; the most highly developed EM methods in terms of interpretation. Twodimensional inversion algorithms are not only available, but comparison of various codes is possible. Tezkan and Dautel (1997) show an excellent example of a 2-D inversion on the RMT data. The RMT method can be limited by the lack of available transmitting signal in remote areas such as the INEL. The CSAMT data contain the lowest frequency data at 10 $\mathrm{Hz}$ and the existence of bedrock beneath the waste is discernible in the phase data. Two 
horizontal magnetic dipole are used as a distant source, and data were collected with 15 feet dipoles for both polarization modes. CSAMT data are full tensor electric and magnetic field measurements, while the RMT system reports only the diagonal impedance.

Geoelectric methods have always been an essential tool in geophysical exploration, and a traditional Induced Polarization (IP) survey and a new capacitive electric field system were included in the study. The prototype Geometrics OhmMapper was tested and data were compared to that collected with the traditional galvanic system by Auriga with excellent results. The OhmMapper results had a consistent upward bias when compared to the Auriga measurements and the system is very sensitive to coupling when small dipole antenna ( 2.5 $\mathrm{m}$ ) are used, but data acquisition rates are very rapid.. Two-dimensional IP inversion results of dipole-dipole data are spectacular (Frangos, 1997) in defining the waste. The resistivity results mapped conductivity variations in both the host and the waste. A rapid IP system would be an important contribution to the toolbox of geophysics techniques for exploration of the shallow subsurface.

\section{CONCLUSIONS}

Electromagnetic instruments and interpretational techniques are well developed and can answer many of the questions posed in environmental investigations such as the location of vertical boundaries of conductive targets. Single component magnetic field systems are excellent for rapid anomaly detection, whereas electric field measurements are necessary for high-resolution, multidimensional inversion. Future work in instrumentation should include plane wave measurements to higher frequencies, a rapid IP system, and a look at transient electric field measurements. Interpretational in $3 \mathrm{C}$ time-domain data and electrical field transients are fertile also areas of research.

\section{ACKNOWLEDGMENTS}

This project was funded by the US Department of Energy, Office of Environmental Management under contract number ID0-6-LF-21.

\section{REFERENCES}

Alumbaugh, D.L., and Newman, G.A., 1997, Electromagnetic Inversion for Environmental Site Characterization: In the proceedings of the 3rd European EEGS Conference, Aarhus, Denmark, Sept. 1997

Frangos, W., 1997, IP and resistivity survey at the INEL Cold Test Pit: In the proceedings of the 3rd European EEGS Conference, Aarhus, Denmark, Sept. 1997

Stemberg, B.K., and Poulton, M.M., 1994, High-resolution subsurface imaging and neural network recognition: In the proceedings of the SAGEEP, Orlando, FL.

Tezkan B., and Dautel, S. 1997, A Radiomagnetotellurics Survey of the Idaho National Engineering Laboratory, Cold Test Pit: In the proceedings of the 3rd European EEGS Conference, Aarhus, Denmark, Sept. 1997.

Wright, D.L., Grover, T.P., Labson, V.F., and Pellerin, L., 1996, The Very Early Time Electromagnetic (VETEM) system: First Field Test Results In the proceedings of the SAGEEP, Keystone, CO. 